\title{
Intramyocardial dissecting hematoma of right ventricle following a myocardial infarction
}

Daniel Martinez Gonzalez * (), Clara Jaqués Andrés and Raúl Vicho Pereira

(c) 2018 Springer-Verlag GmbH Germany, part of Springer Nature and ESICM

A 79-year-old man with a medical history of hypertension, diabetes mellitus with polyneuropathy, dyslipidemia, and transient ischemic attack was admitted to the ICU for myocardial infarction after primary percutaneous revascularization (coronary angiography showed non-occlusive lesions in circumflex and posterior descending arteries and two stents were implanted). Dual antiplatelet therapy (aspirin + ticagrelor) and low molecular weight heparin (bemiparin) had been initiated. Twelve hours after admission, the patient experienced refractory angina. An electrocardiogram showed ST segment elevation in inferior leads and recurrence of elevated cardiac enzymes (troponin-T $1000 \mathrm{ng} / \mathrm{L}$ ). A new coronary angiography was performed but did not reveal further lesions or complications related to the previous procedure. The following days the patient

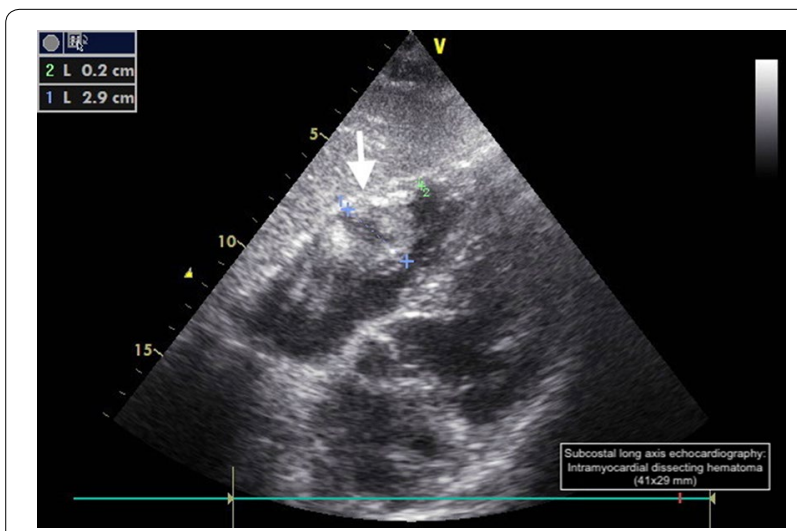

Fig. 1 Subcostal long axis echocardiography: intramyocardial dissecting hematoma $(41 \times 29 \mathrm{~mm})$

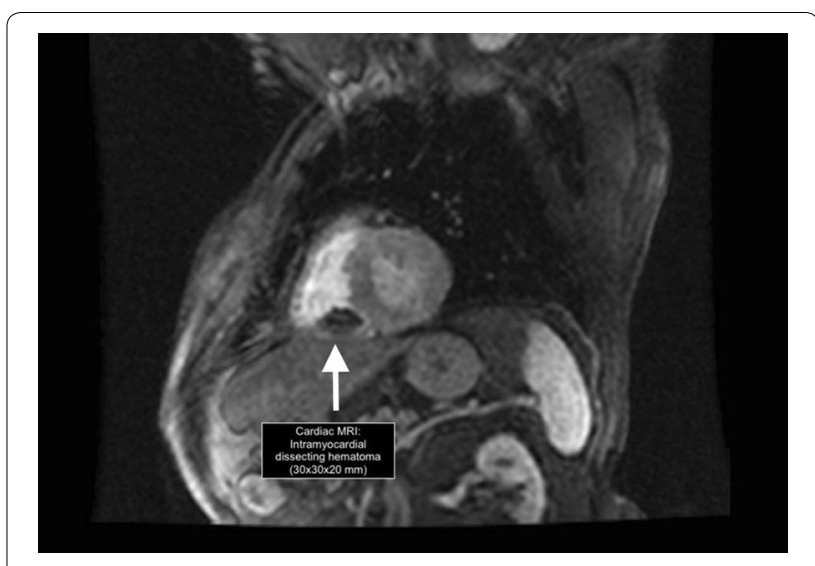

Fig. 2 Cardiac MRI: intramyocardial dissecting hematoma (30×30×20)

remained asymptomatic. Repeat electrocardiograms demonstrated persistent ST segment elevation in inferior leads and negative $\mathrm{T}$ wave in anterolateral leads. Cardiac enzymes gradually decreased. A follow-up cardiac ultrasound demonstrated thickening up to $29 \mathrm{~mm}$ of the right ventricular wall in the subcostal long and short axes (Fig. 1). The ultrasound findings were confirmed by a cardiac MRI, showing an intramyocardial mass measuring $30 \times 30 \times 20 \mathrm{~mm}$ affecting the inferior wall of the right ventricle consistent with a dissecting hematoma (Fig. 2).

\section{Electronic supplementary material}

The online version of this article (https://doi.org/10.1007/s00134-018-5115-y) contains supplementary material, which is available to authorized users.

Received: 14 February 2018 Accepted: 22 February 2018 Published online: 10 March 2018

*Correspondence: danielmartinezgonzalez83@gmail.com

Clinica Planas, Palma de Mallorca, Mallorca, Spain

\section{实

